\title{
Mediating Roles of Corporate Goal-Setting, Goal-Orientation and Corporate Ethical Values on Work Attitudes of Bank Employees
}

\author{
Ogunyemi Ajibola Olusoga ${ }^{1}$, Samuel. S. Fasanmi ${ }^{1} \&$ Onunkun Olubunmi ${ }^{2}$ \\ ${ }^{1}$ Department of Psychology, Olabisi Onabanjo University, Ago-Iwoye, Nigeria \\ ${ }^{2}$ Department of Guidance and Counseling, Olabisi Onabanjo University, Ago-Iwoye, Nigeria. \\ Correspondence: Samuel. S. Fasanmi, Olabisi Onabanjo University, Ago-Iwoye, Nigeria
}

Received: April 4, 2018

doi:10.5430/bmr.v7n2p1
Accepted: April 16, 2018

Online Published: April 24, 2018

\begin{abstract}
The present study was conducted to examine the mediating roles of corporate goal setting and goal orientation in corporate ethical values and work attitudes of bank employees in Nigeria. Correlation coefficients and regression analysis were employed. Results showed, among other things, that there was a significant contribution of corporate ethical values to work attitudes of bank employees in Nigeria $(t=8.119, \mathrm{p}<.05)$, significant mediating roles of both corporate goal setting and goal orientation in the contribution of corporate ethical values to work attitudes of bank employees in Nigeria. It was recommended, among other things, that organizations should set specific, attainable goals and foster performance goal orientation among employees.
\end{abstract}

Keywords: corporate goal-setting, goal-orientation, corporate ethical values and work attitudes

\section{Introduction}

Globally, work attitudes have received considerable attention from scholars in the fields of organizational, social, career, managerial, and personnel psychology. For any organization to compete favourably in today's competitive business environment, employees' attitudes and commitment towards work go a long way in determining employees' performance and organizational productivity (Germain \& Cumming, 2010; Johnson, Hong, Groth, \& Parker, 2010; Pickles, King, \& Belan, 2012). Banks play a critical role in the uplift of the economy of any country by providing a financial infrastructure in the services sector. In Nigeria, the banking sub-sector has achieved remarkable growth, and each bank aims at outdoing the others in the race of capturing maximum market share by offering quality financial products and services to their customers. Falola, Ibidunni, and Olokundun (2014), like many other researchers, have confirmed that the attitudes of its employees affect performance and have considerable influence on an organization's goal achievement.It is therefore essential to investigate the influence of certain factors on employees' work attitudes.

Attitude is a hypothetical construct that represents an individual's degree of like or dislike for an item or attitude object. Employees have attitudes or viewpoints about many aspects of their jobs, their careers, and their organizations. Attitudes are a way of thinking, and they shape how we relate to the world both in work and outside of work. Unlike personality which is relatively enduring, attitudes are expected to change as a function of experience. Olson, Vernon, and Harris (2013) argued that hereditary variable may affect attitudes but believe that they may do so indirectly. According to some psychologists, most attitudes are the result of either direct experience or observational learning from the environment. For any organization to operate, function well, and achieve the aims and objectives for which it is set up, there must be workers working together in the work environment. These employees are expected to put in their best for optimal performance. This can only materialize when workers' degree of likeness for their jobs or towards work is very high. In other words, optimal organizational performance is positively associated with work attitudes of employees. Employees' work attitudes thus become very important to management in the discharge of their responsibilities and formulation of policies. Weiss (2002) suggests that we form attitudes towards our jobs by taking into account our feelings, beliefs, and behaviour. Arrey (2013) opines that Nigerians generally have a poor attitude to work. Like most other general statements, the one about attitude to work in this country may be true without necessarily being an accurate assessment of the situations. He identified the following three components of work attitudes: Affective, cognitive, and behavioural components. The affective component of an individual's attitudes deals with the feelings or emotions of this individual about an object. This is seen on the basis of the kinds of behaviour which indicate an individual's feelings. We could therefore state that the affective component of attitude of an 
individual relates to the emotional reactions and verbal expressions of the individual to a given object. The cognitive component refers to the individual's knowledge, thoughts, beliefs or ideas about a particular object. Thus this describes the object in some way. For example, an individual might say that an object (a person in this case is wicked). He has made a statement relating to the bad aspects of quality of the object. The statement of belief may also be directed to the future. A worker could for instance say that he believes that the new managing director will make things better for them. The behavioural component consists of the individual's overt non-verbal actions toward an object. It views attitudes as consisting of the individual's action tendencies toward an object or person. Action tendency should be seen as the disposition to take action of some kind, that is, to display particular behaviour towards a specific object. Efforts to investigate the variables that could influence employees' work attitudes are therefore worthwhile. Although so many personal and environmental factors could impact employee work attitudes, our concern in this study is the influence of corporate ethical values.

Ethical values are a set of established principles organizations aspire to observe in the process of doing business. Ethical values of an organization, also known as corporate ethical values, determine the acceptable and responsible behaviour expected to be demonstrated by the staff or employees when dealing with customers. The Business Dictionary defines ethical values as the set of established principles governing virtuous behaviour. The most common ethical values found in corporate literature include integrity, fairness, honesty, trustworthiness, respect, and openness. Usually, an organization has a Code of Ethics which its employees are expected to strictly adhere to in the course of performing their tasks. Corporate ethical values provide employees with an understanding and knowledge of what their organizations expect from them in terms of responsibilities and behaviour. They reflect the organization's standards and establish realistic modes of behaviour that applies to everyone in the establishment, from the board of directors to the newest employee. An organization can define corporate ethical values behaviour by outlining what it considers a fair and just treatment of employees and customers. These ethical values are defined largely by behaviours and values that govern a business environment. Corporate ethical values have been studied in a number of ways to understand how they influence the work attitudes, behaviour, and action of employees. It is suspected, and is therefore hypothesized that the relationship between corporate ethical values and work attitudes of bank employees could be mediated by corporate goal setting and goal orientation. This is indeed the focus of this study.

Goals have a pervasive influence on employee behaviour and performance in organizations and management practice (Locke \& Latham, 2002). Nearly every modern organization has some form of goal setting in operation. Programmes such as management by objectives, high performance work practices, management information systems, benchmarking, stretch targets, as well as systems thinking and strategic planning, include development of specific goals. Goal setting is one of the popular therapies in organizational psychology. The theory of goal setting was introduced by Locke in 1968 and has enjoyed a substantial review in the psychological arena over the past three decades (Tubbs, 2014). Goal setting involves the development of an action plan designed to motivate and guide a person or group toward a goal (Grant, 2012). It is a motivational technique used by both individuals and organizations to improve performance (Hinsz, 2015). Goal setting is in fact the underlying explanation for all major theories of work motivation. Managers widely accept goal setting as a means to improve and sustain employee performance. Based on hundreds of studies, the major finding of goal setting is that individuals who are provided with specific, difficult but attainable goals perform better than those given easy, non-specific, or no goals at all (DuBrin, 2012).

The earliest conceptualizations of goal orientation were proposed in the 1970s by the educational psychologist J.A. Eison. Goal orientation is an individual disposition toward developing or validating one's ability in achievement settings (VandeWalle, 1997). Due to the many theoretical and practical applications of goal orientation, it is important to understand the construct and how it relates to other variables. Dweck (1986) conceptualized goal orientation as a two-dimension construct. Individuals with a learning goal orientation (LGO), sometimes referred to as mastery goal orientation, seek to develop their competence by acquiring new skills and mastering new situations. Unlike individuals with performance goal orientation (PGO), they are not concerned about their performance relative to others, but rather with furthering their understanding of a given topic or task (VandeWalle \& Slocum, 2001).Individuals with a performance goal orientation seek to demonstrate and validate the adequacy of their competence in order to receive favourable judgments and avoid negative judgments. In a nutshell, goal orientation is a dichotomous variable, categorized according to whether individuals primarily strive to enhance their knowledge, skills, and competence, referred to as a learning orientation, or generally attempt to demonstrate their abilities and expertise, referred to as a performance orientation. Given that there is a positive relationship between corporate goal setting and performance since the most effective performance seems to result when goals are specific and challenging, and also a positive relationship between employee attitudes and performance, the impact of corporate ethical values on work attitudes may 
be mediated by variables such as corporate goal setting and goal orientation. This will therefore be examined in the present study.

\section{Literature Review}

Cognitive dissonance theory posits that when a person is faced with inconsistencies among attitudes or behaviours, he or she tries to resolve the dissonance by changing an attitude or modifying behaviour (Festinger, 1957). People always encounter conflict between attitudes and behaviours. People are motivated to reduce the negative feelings caused by dissonance by fitting dissonant elements together. A cognitive element can be something a person believes, a behaviour engaged, or observations about surroundings. The feeling of dissonance depends on both the importance and number of dissonant elements.

Dissonance reduction can occur either by eliminating, adding, or changing elements. Dissonance can be reduced by increasing the attractiveness of the chosen alternative relative to those not chosen. The individual usually exerts considerable effort to minimize dissonance in their environment, which put in an organizational context, implies employees strive and desire congruence between their ethical standards and that of their organization. Where dissonance or incongruence is perceived, this will lead to dissatisfaction (Viswesvaran, Deshpande, \& Joseph,1998) and employees would want to minimize this. The minimization could lead to withdrawal and resignation from the organisation. This was demonstrated in Fasanmi (2016) which affirmed that work attitude have direct effects on the negative relationship between citizenship behaviour and turnover intent.

Viswesvaran, Deshpande, \& Joseph, (1998) were of the opinion that in a set of three entities-individual and attitude towards two entities, if the individual is to have both attitude positive, then the two entities should be positively related. Since most individuals strive to be ethical (by their own decision rule) and successful, we have positive relationship between the individual and perceptions of success and perceptions of support for ethical behaviour. It is likely that top managers reflect success in most organizations. Now, if there is a perception that top managers in an organisation do not support ethical behaviour, a dissonance results. This dissonance contributes to dissatisfaction with existing conditions in the work place (p. 367).

The balance theory (Heider, 1958) describes elements in the environment as appearing in groups of three. The resulting attitude structures are called triads. Each triad consists of (1) a consumer, (2) a product brand, and (3) some other person. In balance theory, both the consumer and some other person evaluate the object as either positive or negative, and the consumer also has an evaluation of the other person. The theory specifies that people desire relations among elements in a triad to be harmonious, or balanced. If they are not, a state of tension results until perceptions are changed and balance is restored. People alter perceptions in order to make relations among them consistent. For instance, if a manager's job causes him to behave unethically (due to pressure from superiors), and the manager does not like unethical behaviour, then the manager will not like his job, because it causes him to be unethical. Researches in this direction have tried to empirically explore the relationship between work attitude and corporate ethical values (Schwepker Jr., 2001; Koh \& Boo, 2001). Findings from these works are not unconnected to the fact that where a manager experiences moral conflict due to lack of fit between his personal ethical standard, and that of the organisation, but did not resign, this tends to lead to reduced job satisfaction (Koh \& Boo, 2001) and lower commitment (Paterson, 2003; Rozen, DePelsmacker, \& Bostyn, 2001). In related studies, Fasanmi (2018) found that greater affective commitment is associated with stronger organizational citizenship behaviour, and the higher the perceived level of empowerment, the higher the level of organisational commitment, and the lower the intention to leave the organisation.

Several studies have been conducted on the influence of corporate ethical values on work attitudes. However, these studies have been carried out primarily in the United States, Europe, and Asia (Adams, Taschian, \& Stone, 2001). Despite the importance of these variables, one of the regions that have been neglected by researchers is sub-Saharan Africa despite the fact that investigators (e.g., Irwin, 2011; Kumasey, Bawole, \& Hossain, 2016; Okpara, 2003) have recognized that culture or country has an influence on employee attitudes. For instance, extensive reviews of literature on this issue show that very little research has been undertaken in Nigeria to examine this problem. Furthermore, the mediating roles of corporate goal setting and goal orientation have not been investigated at all. Due to lack of empirical research on this topic, and to further enhance our understanding of the centrality of these variables to employees' productivity and, by extension, organizational success, the present study investigates the influence of corporate ethical values on work attitudes of bank employees in Nigeria and how it is mediated by corporate goal setting and goal orientation.

This study has potential benefits for both scholars and practitioners alike. First, it is important to examine whether these constructs that apply in the United States and other developed countries also hold in a developing country like Nigeria. Second, given the important influence work attitudes have on variables that determine organizational success, 
it is imperative to understand the factors that influence work attitudes and the nature of their influence. Third, from an academician perspective, the study is expected to enhance scholars' understanding of the influence of corporate ethical values in a non-western context, thus hopefully stimulating further research in this area. Finally, from a practical standpoint, this study could provide practitioners, especially bank managers with valuable information for making better decisions in recruitment, selection, promotion, and training of personnel.

\section{Hypotheses}

1. There is a significant contribution of corporate ethical values to work attitudes of bank employees in Nigeria.

2. There is a significant mediating effect of corporate goal setting in the contribution of corporate ethical values to work attitudes of bank employees in Nigeria.

3. There is a significant mediating effect of goal orientation in the contribution of corporate ethical values to work attitudes of bank employees in Nigeria.

\section{Method}

This section showcased the methods adopted for this research.

\subsection{Research Design}

The design adopted by the researchers for this study was expost-facto survey design.

\subsection{Population of the Study}

The population of this study consisted of all employees of commercial banks in the six States of South-West, Nigeria. The study was conducted in July 2017.

\subsection{Participants}

A sample of 162 employees was chosen through stratified random sampling technique. The population was divided into three strata: Ekiti and Ondo States, Lagos and Ogun States, and Osun and Oyo States, being the six States making up South-West, Nigeria. Three branches of three commercial banks were then chosen from each stratum through simple random sampling technique, and from each branch, 54 employees were chosen also through accidental sampling technique. The participants consist of $45.7 \%$ male (74) and $54.3 \%$ of female (88).

\subsection{Instrumentation}

(i) Bank Employees' Work Attitude Scale (BEWAS)

The Bank Employees' Work Attitude Scale (BEWAS) was developed by the researchers to assess bank employees' attitudes to work. It contains 17 items in a 5 -point Likert type with responses ranging from $1=$ Strongly disagree to $5=$ Strongly agree. Examples of items on the scale are My work is challenging and interesting and, In my department, we cooperate to get the work done. The BEWAS was administered on 25 randomly selected bank employees in Ijebu-Ode metropolis. After a two-week interval, the scale was again administered on the same set of participants. An analysis of the results obtained revealed a significant stability coefficient of .67, showing that the scale is reliable. A Cronbach's alpha of .78 was also reported for the instrument, indicating that the items on the scale are internally consistent with one another. The scale also yielded expected significant positive correlations $(r=.417, p<.05)$ with the Job Descriptive Index (JDI; Smith, Kendall, \& Hulin, 1969) evidencing the concurrent validity of the BEWAS. The reliability index in the present study is $\alpha=.81$.

\section{(ii) Corporate Ethical Values Scale (CEVS)}

The Corporate Ethical Values Scale (CEVS) was developed by Hunt, Wood, and Chonko (1989) to capture employees' perception about the prevalence of corporate ethical values in their organizations. It contains five items in a 5-point Likert type scale having responses ranging from $1=$ Strongly disagree to $5=$ Strongly agree. This scale has been repeatedly used by many researchers have been concerned with corporate ethical values in different organizations (e.g., Baker, Hunt, \& Andrew, 2006; Valentine \& Barnett, 2007; Valentine, Godkin, Fleischman, Kidwell, \& Page, 2011). Examples of items on the scale are Top management in my company has let it be known in no uncertain terms that unethical behaviour will not be tolerated and, In order to succeed in my company, it is often necessary to compromise one's ethics. The developers reported a Cronbach's alpha of .79 as evidencing internal consistency of the scale. The scale is drawn from previous definitions and research in this area (Alluto, Hrebiniak, \& Alonzo, 1973; Becker, 1960; Buchanan, 1974). A factor analysis carried out by the developers indicated a unidimensional structure which provides evidence of its construct validity. The reliability index in the present study is $\alpha=.78$. 


\section{(iii) Corporate Goal Setting Scale (CGSS)}

The Corporate Goal Setting Scale (CGSS) was developed by the researchers using sound psychometric procedures. It was based on the popularly accepted SMART model of corporate goal setting. It contains six items in a 5-point Likert type scale with responses ranging from $1=$ Strongly disagree to $5=$ Strongly agree. Examples of items on the scale are Goals set by my organization are achievable and Goals set by my organization are realistic. The researchers administered the scale on 25 randomly selected bank employees in Ijebu-Ode metropolis. After a two-week interval, the scale was again administered on the same set of subjects. An analysis of the results obtained revealed a significant stability coefficient of .72, showing that the scale is reliable. A Cronbach's alpha of .79 was reported for the CGSS, while expert opinion was used to establish its content validity. The reliability index in the present study is $\alpha=.79$.

(iv) Goal Orientation Scale (GOS)

The Goal Orientation Scale (GOS) was developed by Button, Mathieu, and Zajac (1996) to classify individuals into those with learning goal orientation and those with performance goal orientation. It consists of 13 items in a 5-point Likert type scale having responses ranging from $1=$ Very much unlike me to $5=$ Very much like me. Examples of items on the scale are I enjoy challenging and difficult tasks at work where I'll learn new skills and I am concerned with showing that I can perform better than my coworkers. The developers reported a Cronbach's alpha of 0.82 for the GOS showing that the items are internally consistent with one another, and a test-retest reliability coefficient with a one-month interval yielded .71 evidencing the stability of the scale. The validity of the entire scale was determined through significant group difference between employees with learning goal orientation and employees with performance goal orientation.Exploratory factor analysis (EFA) and confirmatory factor analysis (CFA) were used to assess the construct validity of the scale. EFA results showed that the GOS had a two-factor structure (ego and task orientation), and CFA confirmed this structure $\left(X^{2}=14.83, p<.05\right)$. Furthermore, significant correlations between goal orientation and behavioural regulations served to provide initial evidence for the convergent validity of the measure. The scale also has good fit indices, namely, Adjusted Goodness of Fit Index (AGFI = .95), Goodness of Fit Index $(\mathrm{GFI}=.97)$, Comparative Fit Index $(\mathrm{CFI}=.97)$, Normal Fit Index $(\mathrm{NFI}=.97)$, Tucker-Lewis Index $(\mathrm{TLI}=.98)$, Root Mean Square Error of Approximation (RMSEA $=.045$ ), AND Standardized Root Mean Square Residual (SRMR $=.049$ ). The reliability index in the present study is $\alpha=.75$.

\subsection{Procedure}

The instruments were administered on the participants personally by the researcher after meeting and obtaining permission from the bank managers. The subjects were briefed on how to fill the questionnaires and an appeal was made for frank and sincere responses, with assurance that information given would be treated as strictly confidential and used only for the purpose of this study.The instruments were then distributed and later collected and scored. A 100\% return rate was achieved.

\subsection{Method of Data Analysis}

Data collected were tested by means of correlation coefficients and regression analysis. Tests were carried out at the 0.05 significance level. All analyses were carried out with the aid of the IBM SPSS Version 22 software.

\section{Results}

Results of the generated hypotheses were presented in this section. Acorrelation matrix of the scaled variables in the study was also presented in this section.

Table 1. Correlation matrix for the relationship among corporate goal setting, goal orientation, corporate ethical values, and work attitudes

\begin{tabular}{lllll}
\hline & GOALSET & GOALORI & COETHIC & WORKATT \\
\hline GOALSET & 1 & $.327^{*}$ & $.174^{*}$ & $.220^{*}$ \\
GOALORI & & 1 & $.386^{*}$ & $.316^{*}$ \\
COETHIC & & 1 & $.418^{*}$ \\
WORKATT & & & & 1 \\
\hline
\end{tabular}

*Correlation is significant at 0.05 level (2-tailed)

Note: GOALSET = Corporate Goal Setting; GOALORI = Goal Orientation $;$ COETHIC = Corporate Ethical Values; WORKATT $=$ Work Attitudes 
Table 1 showed correlation matrix of the scaled variables in the study. It was revealed that significant and positive inter-correlations among corporate goal setting, goal orientation, corporate ethical values, and work attitudes. The strongest relationship was between corporate ethical values and work attitudes $(r=.418, p<.05)$. This was followed by relationships between goal orientation and corporate ethical values $(r=.386, \mathrm{p}<.05)$, corporate goal setting and goal orientation $(\mathrm{r}=.327, \mathrm{p}<.05)$, goal orientation and work attitudes $(\mathrm{r}=.316, \mathrm{p}<.05)$, corporate goal setting and work attitudes $(\mathrm{r}=.220, \mathrm{p}<.05)$, and corporate goal setting and corporate ethical values $(\mathrm{r}=.174, \mathrm{p}<.05)$.

Hypothesis one stated that there is a significant contribution of corporate ethical values to work attitudes of bank employees in Nigeria.

Table 2.Coefficient of the Regression Analysis for the Contribution of Corporate Ethical Values to Work Attitudes of Bank Employees in Nigeria

\begin{tabular}{lllll}
\hline & Unstandardized $\beta$ & Standardized $\beta$ & $t$ & $p$ \\
\hline Constant) & 12.276 & & 7.884 & .000 \\
Corporate Ethical Values & .207 & .238 & 8.119 & .000 \\
\hline
\end{tabular}

Table 2 revealed that there is a significant contribution of corporate ethical values to work attitudes of bank employees in Nigeria $(\beta=.238, \mathrm{t}=8.119: \mathrm{p}<.05)$. The table further revealed that corporate ethical values will contribute $24 \%$ to the work attitudes of bank employees in Nigeria. Thus, hypothesis one which stated that there is a significant contribution of corporate ethical values to work attitudes of bank employees in Nigeria is confirmed.

Hypothesis two stated thatthere is a significant mediating effect of corporate goal setting in the contribution of corporate ethical values to work attitudes of bank employees in Nigeria.

Table 3. Multiple Regression Analysis for the mediating effect of corporate goal setting in the contribution of corporate ethical values to work attitudes

\begin{tabular}{llllllllll}
\hline Model & $R$ & $R^{2}$ & $\begin{array}{l}\text { Adjusted } \\
R^{2}\end{array}$ & Std. Error & $R^{2}$ change & F change & $d f 1$ & $d f 2$ & $\begin{array}{l}\text { Sig. } \\
\text { Change }\end{array}$ \\
\hline 1 & $.853^{\mathrm{a}}$ & .728 & .722 & 10.341 & .728 & 103.664 & 1 & 160 & .000 \\
2 & $.924^{\mathrm{b}}$ & .854 & .845 & 9.8245 & .081 & 17.329 & 1 & 159 & .000 \\
\hline
\end{tabular}

${ }^{a}$ Predictors: (Constant), corporate ethical values

${ }^{b}$ Predictors: (Constant), corporate ethical values, corporate goal setting

Dependent Variable: Work Attitudes

As shown in Table 3, Model 1 included only corporate ethical values and accounted for $72 \%$ of the variance in work attitudes (Adjusted $\mathrm{R}^{2}=.722$ ). The inclusion of corporate goal setting into Model 2 resulted in additional $8 \%$ of the variance in work attitudes $\left(R^{2}\right.$ change $\left.=.081\right)$, and this variance was significant $\{F(1,159)=17.329, p<.05\}$. The null hypothesis is therefore rejected in favour of the alternative hypothesis, leading to the conclusion that there is a significant mediating effect of corporate goal setting in the contribution of corporate ethical values to work attitudes of bank employees in Nigeria.

Hypothesis three stated that there is a significant mediating effect of goal orientation in the contribution of corporate ethical values to work attitudes of bank employees in South-West, Nigeria.

Table 4. Multiple Regression Analysis for the mediating effect of goal orientation in the contribution of corporate ethical values to work attitudes

\begin{tabular}{llllllllll}
\hline Model & $R$ & $R^{2}$ & $\begin{array}{l}\text { Adjusted } \\
R^{2}\end{array}$ & Std. Error & $R^{2}$ change & F change & $d f 1$ & $d f 2$ & $\begin{array}{l}\text { Sig. } \\
\text { Change }\end{array}$ \\
\hline 1 & $.853^{\mathrm{a}}$ & .728 & .722 & 10.341 & .728 & 103.664 & 1 & 160 & .000 \\
2 & $.913^{\mathrm{b}}$ & .834 & .826 & 9.554 & .068 & 13.206 & 1 & 159 & .000 \\
\hline
\end{tabular}

${ }^{a}$ Predictors: (Constant), corporate ethical values

${ }^{b}$ Predictors: (Constant), corporate ethical values, goal orientation

Dependent Variable: Work Attitudes 
Table 4 showed that there is a significant mediating effect of goal orientation in the contribution of corporate ethical values to work attitudes of bank employees. The table revealed that Model 1 included only corporate ethical values and accounted for $72 \%$ of the variance in work attitudes (Adjusted $\mathrm{R}^{2}=.722$ ). The inclusion of goal orientation resulted in additional $7 \%$ of the variance being explained $\left(\mathrm{R}^{2}\right.$ change $\left.=.068\right)$, and this change in work attitudes was significant $\{\mathrm{F}$ $(1,159)=13.206, \mathrm{p}<.05\}$. The null hypothesis is therefore rejected, leading to the upholding of the alternative hypothesis that there is a significant mediating effect of goal orientation in the contribution of corporate ethical values to work attitudes of bank employees in South-West, Nigeria.

\section{Discussion}

Previous studies have neglected to examine the mediating roles of corporate goal setting and goal orientation in corporate ethical values and work attitudes of workers. An attempt was made to investigate this in the current study using a sample of commercial bank employees in South-West Nigeria. Results revealed significant and positive inter-relationships among all the variables of the study, the strongest being between corporate ethical values and work attitudes. The bivariate relationships among corporate goal setting, goal orientation, corporate ethical values, and work attitudes were positive. This indicates possible common factors underlying these variables; that is, corporate goal setting, goal orientation, corporate ethical values, and work attitudes share some characteristics which make them to co-vary in the same direction. By the very nature of these constructs, they are expected to positively correlate. As such, this finding agreed with what one would ordinarily expect.

Results further showed a significant mediating effect of corporate goal setting in the contribution of corporate ethical values to work attitudes of bank employees as well as a significant mediating effect of goal orientation in the contribution of corporate ethical values to work attitudes of bank employees in Nigeria. These findings corroborated DuBrin (2012) and VandeWalle and Slocum (2001) who arrived at similar results.

\section{Limitation of the Study}

The sample size was rather too small for the strength of the statistics adopted for the study. Fasanmi (2017), asserted that the larger the sample size of a population, the lower the variance, and consequently, the better the overall results. The small sample size would surely make resuls generalization very difficult. Thus, it is expedient for future researchers to take into cognizance the number of selected participants in ensuring better results.

Physical distribution of questionnaire to bankers could be very frustrating and cumbersome. Thus, future researchers who are interested in this area of study should ensure to annex other means beyond physical distribution of questionnaire to bankers in other to ensure easy reach to participants and consequently boost the sample size.

The usage of one bank might have sounded good; the uniformity in the culture of the bank could pose a major challenge to the generalization of the results of this study. Organisational culture varies across Nigeria banks, policies also differ.

\section{References}

Adams, J. S., Tashchian, A., \& Stone, T. H. (2001). Codes of ethics as signals for ethical behaviour. Journal of Business Ethics, 29, 199 - 211.https://doi.org/10.1023/A:1026576421399

Alluto, J. A., Hrebiniak, L. G., \& Alonzo, R. C. (1973). Man, motivation, and productivity. Administrative Management Society Bulletin, 1 (August), $1-8$.

Arrey, O. B. (2013). Attitude to Work by Nigerian Workers: A Theoretical Perspective. Global Journal of Management and Business Research Administration and Management, 13(12), 112 - 126.

Baker, T. L., Hunt, T. G., \& Andrews, M. C. (2006). Promoting ethical behaviour and organizational citizenship behaviours: The influence of corporate ethical values. Journal of Business Research, 59(7), 849-857.https://doi.org/10.1016/j.jbusres.2006.02.004

Becker, H. S. (1960). Notes on the concept of commitment. American Journal of Sociology, 6(1), 32 40.https://doi.org/10.1086/222820

Buchanan, B. (1974). Building organizational commitment: The socialization of managers in work organizations. Administrative Science Quarterly, 19(4), 533 - 546.https://doi.org/10.2307/2391809

Button, S. B., Mathieu, J. E., \& Zajac, D. M. (1996). Goal orientation in organizational research: A conceptual and empirical foundation. Retrieved on $12^{\text {th }}$ August, 2017 from http://www.doi.org/10.1006/obhd.1996.D063

DuBrin, A. J. (2012). Essentials of management. Mason, OH: Cengage South-Western. 
Dweck, C.S. (1986). Motivational processes affecting learning.American Psychologist, 41, 1040-1048.https://doi.org/10.1037/0003-066X.41.10.1040

Falola, H. O., Ibidunni, A. S., \& Olokundun, M. A. (2014). Incentives packages and employees' attitudes to work: A study of selected government parastatals in Ogun State, South-West, Nigeria. International Journal of Research in Business and Social Science, 3 (1), 63 - 74.

Fasanmi S. S (2017). Computer Statistical analysis in Social Sciences in O. O. Adetola, R. Aborishade, and S. Fasanmi (eds), Research Methods in Social and Sciences.(pp 68-106). Ibadan University Press. ISBN: 978-978-8529-35-4.

Fasanmi S. S. (2016). Organizational citizenship behavior and turnover intent: a path analysis of Nigeria bankers' behavioural variables. American Journal of Applied Psychology; 5(6), 51-59.https://doi: 10.11648/j.ajap.20160506.13.

Fasanmi S. S. (2018). Effects of commitment, justice and empowerment on organisational citizenship behaviour and turnover intent among Nigeria bankers. Ife PsychologIA, 26(1) 16 - 44.

Festinger, L. (1957). A theory of cognitive dissonance. Stanford, CA.: Stanford University Press.

Germain, P. R. \& Cumming, G. G. (2010). The influence of nursing leadership on nurse performance: A systematic literature review. Journal of Nursing Management, $18(4), \quad 425$ 439.https://doi.org/10.1111/j.1365-2834.2010.01100.x

Grant, A. M. (2012). An integrated model of goal-focused coaching: An evidence-based framework for teaching and practice. International Coaching Psychological Review, 7(2), 146 - 165.

Heider,F.(1946).AttitudesandCognitiveOrganisation.JournalofPsychology,21,107-112.https://doi.org/10.1080/00223 980.1946.9917275

Hinsz, A. F. (2015). The managed heart: Commercialization of human feelings. Berkeley: University of California Press.

Irwin, J. (2011). Doing business in South Africa: An overview of ethical aspects. London: Institute of Business Ethics.

Johnson, A., Hong, H., Groth, M., \& Parker, S. K. (2010). Learning and development: Promoting nurses' performance and work attitudes. Journal of Advanced Nursing, 1(1), 1365 - 2648.

Koh,H.C.,\& Boo,E.H.Y.(2004). Organisational Ethics and Employee Satisfaction and Commitment. Management Decision, 42 (5/6), 677-693.https://doi.org/10.1108/00251740410538514

Kumasey, A. S., Bawole, J. N., \& Hossain, F. (2016). Organizational commitment of public service employees in Ghana. International Review of Administrative Sciences. July 26.

Locke, E. A. \& Latham, G. P. (2002). Building a practically useful theory of goal setting and task motivation. American Psychologist, 57 (9), 705 - 717.https://doi.org/10.1037/0003-066X.57.9.705

Okpara, J. O. (2003). Can corporate ethical codes of conduct influence behaviour? An exploratory study of financial managers in a developing economy. A Paper Presented at the XI International Conference, Brussels, Belgium. July $11-13$.

Olson, J. M., Vernon, P. A., \& Harris, J. A. (2013). The heritability of attitudes: A study of twins. A Paper Presented at the University of British Columbia.

Peterson,D.K.(2003).TheRelationshipbetweenEthicalPressure, RelativisticMoralBeliefsandOrganisationalCommitme nt. JournalofManagerialPsychology, 18(6),557-572. https://doi.org/10.1108/02683940310494386

Pickles, D., King, L., \& Belan, I. (2012). Undergraduate Nursing students' attitudes towards caring for people with HIV/AIDS. Nurse Education Today, 32, 15 - 20.https://doi.org/10.1016/j.nedt.2011.01.008

Rozen, I., De Pelsmacker, P., \& Bostyn, F. (2001). The Ethical Dimension of Decision Processes of Employees. Journal of Business Ethics, 33, 87-99. https://doi.org/10.1023/A:1017536222355

Schwepker,Jr.,C.H.(2001).EthicalClimate'sRelationshiptoJobSatisfaction,OrganisationalCommitment, andTurnoverI ntentionintheSalesforce. Journal of Business Research, 54, 32. https://doi.org/10.1016/S0148-2963(00)00125-9

Smith, P. C., Kendall, L. M., \& Hulin, C. L. (1969). The measurement of satisfaction in work and retirement. Chicago: Rand McNally. 
Tubbs, E. R. (2014). Subjective, psychological, and behavioural effects of threat and challenge appraisal. Journal of Personality and Social Psychology, 65, 248 - 260.

Valentine, S. \& Barnett, T. (2007). Perceived organizational ethics and the ethical decisions of sales and marketing personnel.Journal of Personal Selling and Sales Management, 27(4), $373 \quad-\quad 388$. https://doi.org/10.2753/PSS0885-3134270407

Valentine, S., Godkin, L. V., Fleischman, G. M., Kidwell R. E., \& Page, K. (2011). Corporate ethical values and altruism: The mediating role of career satisfaction. Journal of Business Ethics, 101(4), 509 - 523. https://doi.org/10.1007/s10551-011-0739-7

VandeWalle, D. (1997), Development and validation of a work domain goal orientation instrument. Educational and Psychological Measurement, 8, 995-1015.https://doi.org/10.1177/0013164497057006009

VandeWalle, D. C. \& Slocum, J. W. (2001). The role of goal orientation following performance feedback. Journal of Applied Psychology, 86, 629 - 640.https://doi.org/10.1037/0021-9010.86.4.629

Viswesvaran, C., Deshpande, S. P., \& Joseph, J. (1998). Job Satisfaction as a Function of Topanagement Support for Ethical Behaviour: A Study of Indian Managers. Journal of Business Ethics, 17(4), 365-371. https://doi.org/10.1023/A:1017956516324

Weiss, H. M. (2002). Deconstructing job satisfaction. Human Resource Management Review, 12, 175 194.https://doi.org/10.1016/S1053-4822(02)00045-1 